\title{
POLYHEDRA AND THE ABOMINATIONS OF LEVITICUS
}

\author{
DAVID BLOOR*
}

How are social and institutional circumstances linked to the knowledge that scientists produce? To answer this question it is necessary to take risks: speculative but testable theories must be proposed. It will be my aim to explain and then apply one such theory. This will enable me to propose an hypothesis about the connexion between social processes and the style and content of mathematical knowledge.

To do this I shall bring together the ideas of two books. One of these is Imré Lakatos's Proofs and refutations (1976) ; ${ }^{1}$ this describes the history of a mathematical dispute, and it is also a piece of advocacy in the philosophy of mathematics. The other is Mary Douglas's Natural symbols (1973), ${ }^{2}$ which contains an anthropological theory about pollution, ritual, dietary restrictions, and religious cosmologies. The books have a common theme: they deal with the way men respond to things which do not fit into the boxes and boundaries of accepted ways of thinking; they are about anomalies to publicly-accepted schemes of classification. Whether it be a counterexample to a proof; an animal which does not fit into the local taxonomy; or a deviant who violates the current moral norms, the same range of reactions is generated. Both writers have, in their own way and unknown to one another, charted and illustrated this range.

Once the similarity of their conclusions has been spotted, insights can be transferred from one account to the other. The crucial point is that Mary Douglas has an explanation of why there are different responses to things which break the orderly boundaries of our thinking: these responses are characteristic of different social structures. Her theory spells out why this will be so, and describes some of the mechanisms linking the social and the cognitive. This means we should be able to predict the social circumstances which lie behind the different responses which mathematicians make to the troubles in their proofs. The first thing will be to look at Lakatos's philosophy of mathematics in some detail.

* Science Studies Unit, University of Edinburgh, 34 Buccleuch Place, Edinburgh EH8 9JT

I am especially indebted to Professor Mary Douglas for her generous encouragement and help. I have also benefited enormously from the critical and constructive comments of Barry Barnes, Alex Bellamy, Celia Bloor, Ken Caneva, Nicholas Fisher, Donald MacKenzie, Martin Rudwick, Steven Shapin, Fran Wassoff and Peter Whittingham. I am aware that I have only been able to answer some, rather than all, of the questions that they have raised.

This paper started life as an essay review of Imre Lakatos's Proofs and refutations: the logic of mathematical discovery. Cambridge: Cambridge University Press, 1976. I am extremely grateful to the editor of this journal for his patience and understanding in allowing a review to metamorphose in this way.

THE BRITISH JOURNAL FOR THE HISTORY OF SCIENCE Vol. I I No. 39 (1978) 
Everyone remembers the mathematical textbook which begins with long and complicated definitions, announces a surprising theorem, and then develops an austerely compelling proof. Definition; theorem; proof; QED. No, says Lakatos; this is all upside down. What really come at the beginning are not definitions, but problems and conjectured solutions to them. Theorems are conjectures. Like all conjectures they need testing, and proofs, odd though this may sound, are attempts to test them.3 In opposition to the usual dogmatic and 'formalist' ideas about mathematics Lakatos favours a 'fallibilist' approach. He presents himself as a follower of both Popper and Hegel.4

Proofs start with a 'thought-experiment', or exploit some quasiempirical procedure to break down the problematic conjecture, embedding it into what may be a quite distinct body of knowledge. Each step in this decomposition of the theorem becomes a possible source of error. It will fail if exceptions are found to it. Exceptions to the steps of the proof Lakatos calls 'local' counterexamples; exceptions to the original conjecture are 'global' counterexamples. Once a proof has been advanced, the original conjecture is even more vulnerable than it was before, for now it risks local objections as well as the global ones.

The main example Lakatos uses to illustrate this idea is Euler's theorem: that for polyhedra the number of faces $(F)$, edges $(E)$, and vertices $(V)$ are related by the formula $V-E+F=2$. This guess, first put forward in $175^{8}$, can easily be verified for cubes and prisms and pyramids, but does it work for all polyhedra? The history of the conjecture is a history of attempted proofs, counterexamples and revised proofs. The argument lasted until Poincaré's work in I 899 seemed to stop the squabbles.5

Lakatos starts the story with a proof based on the work of Cauchy, Crelle and Cayley. Imagine that the polyhedron is hollow and made of rubber - this is the quasi-experiment. One face is then removed so that now $V-E+F=\mathrm{I}$, provided that the original conjecture is true. The polyhedron is then stretched flat and extra lines are drawn joining the vertices so that the faces turn into sets of (perhaps curvilinear) triangles. Every new edge produces a new face so that the equation $V-E+F=\mathrm{I}$ is not disturbed. The triangles are then removed one by one. This can be done so that the number of edges, faces and vertices that disappear with each removal of a triangle still leaves the equation the same. Finally one triangle is left for which, trivially, $V=3, E=3$ and $F=\mathrm{I}$, so the equation $V-E+F=\mathrm{I}$ still balances. The condition for it holding was that the original conjecture is true; nothing in the proof procedure has altered the value of $V, E$, and $F$; so the original conjecture is true.

$\mathrm{Or}$ is it? First Euler's theorem is attacked with local counterexamples. Can all polyhedra be stretched flat? What about a pictureframe shape? Even if they can be flattened, can the faces always be 
triangulated without disturbing the equation? What about a cube with another cube sitting on top of it in the middle of one of its faces ${ }^{6}-a$ 'crested cube'? A line joining an inner and an outer vertex of the rectangular border around the top cube does not increase the number of faces, so triangulation breaks down here. Criticisms and exceptions like this lead to refinements and qualifications to the proof procedure: it has to be restricted to 'simple' polyhedra that are topologically equivalent to a sphere so that they can be stretched flat when one face has been removed. And it has to be limited to polyhedra with 'simply connected' faces to exclude the ring-shaped areas for which triangulation fails.7

Global objections are considered next. These invariably spark off definitional controversies. For example, what about a cube with another cube hollowed out of the middle? For these 'nested cubes', $V-E+F=4$. They were first spotted by Lhulier in 1812 and rediscovered by Hessel in 1832 ; both men had been looking at crystals which sometimes take this form. ${ }^{8}$ Again, what about two tetrahedra joined at a vertex? Each one singly satisfies the theorem, but the Siamese twin does not: $V-E+F=3.9$ Or what about a cylinder? Here there are no vertices, only 2 edges and 3 faces, so $V-E+F=\mathrm{I}$. The problem is whether these are really counterexamples, or whether they are not exceptions which refute the theorem because they are not the kind of thing the conjecture was meant to cover. After all, what is a polyhedron? At first it may have seemed obvious what it meant for a shape to be 'like' a cube and a prism. Of course a cylinder is not a polyhedron, but why not? The counterexamples make the boundaries of the species look problematic.

This is the origin of those complicated definitions. It emerges that a polyhedron is not to be thought of as a solid, it is a system of polygonal surfaces; and exactly two faces have to meet at every edge; and it must be possible to get from any face to any other without crossing a vertex; and through any arbitrary point it must be possible to draw a plane that will slice the polyhedron into only one polygonal cross section, etc., etc. ${ }^{10}$ These qualifications trace the history of the struggle between those who support the conjecture and those who propose the counterexamples. As Lakatos says, they do not precede the proof, but really come at the end.

So far this could all be accepted without much change in the usual dogmatic view of mathematics. Everyone knows that argument helps to uncover the holes in our reasoning. Won't mathematicians argue until somebody has hit upon a real proof, then the argument has to stop? This misses Lakatos's point. To see why, we must look further into what he says, particularly at what he calls 'concept-stretching'.

\section{II}

We have seen that a proof begins with the invention of a technique or procedure, like stretching or triangulating. This can be carried out on 
a limited number of familiar figures, but everything surrounding this narrow area of accomplishment is, at first, simply darkness. The accomplishment is mute about its own scope and about the broader range of contingencies to which it may come to be related. It says nothing about whether such things as nested cubes or twin tetrahedra do, or even can, exist; or whether they have any relevance to the study of polyhedra.

This approach to proofs may be called 'finitist'." The point is that a proof procedure does not have a set of preordained implications outside the immediate context of use. How it comes to be accorded these implications as that context of use is extended is precisely what Lakatos is investigating. $\mathrm{He}$ is not saying that the implications pre-exist but we do not know what they are: the implications await our creation. In particular, the question of whether there are counterexamples to a proof procedure is not settled in advance.

Our normal habits of thought do not allow us to entertain such a striking idea. Suppose there are no counterexamples to a conjecture: surely there are only two possible explanations? There really are counterexamples, but no-one has noticed them; or the range of cases that could be cited as counterexamples has been exhausted. Is reality not a kind of store-house of all possible cases, and does this not determine whether a theorem is correct or not? Variants of this compelling view are usually dubbed 'Platonism'. Most of us, most of the time, are Platonists. We usually think that mathematical objects or structures fall into a unique, natural set of kinds or sorts, as if there are specially privileged 'real' boundaries which demarcate different kinds of thing. In short we assume a limited stock of Essences or Forms.

This is what Lakatos rejects. He treats mathematical 'kinds' as being our creations. We draw the boundary lines. Classification is our achievement and our problem. Nothing is to be gained by seeing different boundary lines as more or less corresponding to the 'real' ones. But this is not all. For Lakatos the world is so densely populated by objects of all shapes and sizes, and there are so many imaginable procedures that can be based on them, that there is an indefinitely large number of different boundaries that we might reasonably draw. Unlike the sparser, prepackaged picture of the world suggested by Platonism, where there are clear gaps on the shelves between the different kinds of thing, for Lakatos the world is more densely stocked. There will always be some equivalent to that surprising stream of nested cubes, crested cubes, twin-tetrahedra and picture frames which gushed forth and threatened to swamp Euler's conjecture.

Can we escape this difficulty by using very simple principles of classification? Even if we cannot decide what should count as a polyhedron we can surely decide once and for all what is to count as, say, a vertex, or an edge, or a plane? If we retreated into using absolutely simple and perfectly 
understood terms we might build up the more complicated classifications out of these. Then our reasoning would be so clear that everyone would always know exactly what was being said. Decisive proof or decisive disproof would be possible. There might be some verbal differences but at least there would be a nucleus of achievement that would be perfectly secure against further counterexamples or disagreement.

No, says Lakatos again: simple ideas can always be turned into complex ones and the whole problem started again. The belief in a fixed basic vocabulary of perfectly understood terms is an illusion created by our verbal habits. We become habituated to a certain usage in a particular context; it becomes 'obvious', transparent, and direct. We think that we will know exactly how to use the word in all future cases, as if there were a unique and natural way of extending it outside its old range. This is wrong, because new proof procedures can decompose any idea, however simple. They bring to it a new context, suggest new connotations and hence endow it with a new, inner complexity. What the Cauchy proofprocedure did for our idea of polyhedra could be done for any concept including point and line. Our concepts can always be 'stretched'.

Is Lakatos saying that there always will be counterexamples to theorems? In one sense, yes he is: there will always be objects that could be used to make a mockery of our classifications. But potentiality is not actuality; for something to be actually a counterexample requires another step: it depends on its being accorded this status. Being a counterexample is a role which is conferred upon something, and this depends on how it is used. When we say that we 'recognize' things as counterexamples we ought not to mean that we directly apprehend the intrinsic and permanent character of the thing; the visual metaphor, with its usual platonizing connotations, is wrong. We should use the word 'recognize' as we do when we say a man achieves recognition by being honoured. Conferring a knighthood is not revealing that a man was, all along, a knight. Because 'counterexamplehood' is likewise a social achievement, men are incessently pushing and pulling at the boundaries of their concepts, trying to achieve a better or a different order, and of course, using different conceptions of order to suit their different aims. As order is achieved in one place, so it will be disturbed in others. More anomalies will be created, and previous achievements will be thrown out of joint. For example Cauchy used the concept of 'polyhedron' to cover roughly what we would call 'convex polyhedron'. I2 On his usage Euler's conjecture looked like a general theorem that covered all things properly called 'polyhedra'. When this class was stretched to include previously ignored figures, the proof procedure ceased to be generally applicable and the original conjecture was frequently violated. This is not an isolated case; a similar thing happened with the idea of a 'function'.13

On the one hand, then, Lakatos uses his finitist idea of a proof 
procedure to remove guarantees against counterexamples, and on the other he introduces his assumption of complexity and his picture of concept-stretching, which between them guarantee that there always will be things which could be used as counterexamples. Before looking at the great significance of this conclusion we had better consider and answer some objections to how it was reached.

\section{III}

It may be said that Lakatos is making a trivial, purely verbal point: when the meaning of a word is changed then of course sentences that were previously true become false. If the word 'bachelor' is 'stretched' to cover men who merely behave like bachelors then of course it will be false that all bachelors are unmarried men-though in terms of the original meaning it is as true as ever.

This fails to meet Lakatos's point. He is saying that concept-stretching and the redrawing of classificatory boundaries is an integral part of mathematical reasoning. Trying out wider and different applications of concepts, and making the consequent adjustments to theorems and definitions is something that is going on all the time. Changing the meaning of concepts in this way is not a subterfuge to be shrugged off, as if the counterexamples it created were unimportant. ${ }^{14}$ This is because our intellectual judgements are guided by the properties of our overall system of thought, not by its isolated elements. In the interests of overall coherence any particular achievement may be subverted and any theorem may have to be modified: 'You cannot separate refutations and proofs on the one hand and changes in the conceptual, taxonomical, linguistic framework on the other.''5

The Platonist will not be at a loss for an argument to express his distaste for this conclusion. Surely, he will say, if concept-stretching is to be plausible a term cannot be stretched at will.16 A theorem about polyhedra could not really be refuted by citing one of the properties of a cylinder as a counterexample. If the term 'polyhedra' were stretched to cover cylinders it would simply create an ambiguity in the meaning of the word. It would be using it to refer to two different kinds of thing. If we are not to lapse into confusion, then our words must respect the natural boundaries between different sorts of thing. Once this constraint is acknowledged, the Platonist will continue, then Lakatos's claim fails: there is no guarantee that genuine or unambigious counterexamples can be produced merely by reclassification or concept-stretching.

Of course this is precisely what is at issue: are there any boundaries which our words must respect? This is what divides Lakatos from the Platonist in the first place. What gives Platonism its plausibility, and what is correct about the objection in the previous paragraph, is that at any given time there are limits to the amount and direction of concept- 
stretching and reclassification. The exact character of these constraints is indeed an unsolved problem, but one thing is clear; the constraints can be seen as relative, not absolute. They may be explained by pragmatic considerations related to the difficulties of evolving a shared and workable form of knowledge out of the vested interests and habits of the past. They need not be explained by the alleged need of our words to reflect the ultimately real demarcations between things. We must remember the extensive freedom we have exercised in the past in redrawing the accepted boundaries between different sorts of thing. In the history of science, model has been piled on model, metaphor upon metaphor. Add to this the varied interests which knowledge has served, and the constraints felt by the Platonist seem more like historical contingencies than timeless necessities.

We can now leave behind the trivializing idea that criticism in mathematics merely removes error and reveals truth; the situation is more complicated and more interesting than that. Lakatos is saying that the stability and scope of every theorem is precarious: critical argument and adjustment is in principle endless; there is no final truth to reveal, only a ramified and interlocking network of claims and counterclaims to be balanced and stabilized. ${ }^{7}$

There is, however, a further step which Lakatos does not take but which is suggested by his picture. If the stream of potential counterexamples is endless, then the processes whereby we accord, or fail to accord, recognition of them must also be endlessly at work. Without their remorseless operation and that of the forces which govern them, there would be neither order nor coherence in mathematical knowledge. Its classifications, its counterexamples and its theorems would have no agreed relations to one another. The great significance of Lakatos's work is that it makes the forces which govern the response to anomaly constitutive of mathematical knowledge: they are a necessary part of that knowledge.

A metaphor may help. We can say that Lakatos has shown us that mathematics is something that has to be 'negotiated'. Logically it is totally underdetermined, but if it is to be real knowledge, something objective rather than a confusion of subjective opinion, then it must be determined somehow. The answer is that it is socially determined in the course of negotiations: mathematics is whatever is the outcome, and nothing more. Lakatos, however, has given us only an abstract account of these negotiations. Put bluntly, things are at stake, but Lakatos does not tell us what, so we only have half the story. To get the whole story we need to know if there are any general patterns in these endlessly necessary negotiations, and what the currency is in terms of which profits and losses are calculated. What investments do men have in changing or in maintaining the boundaries of mathematical concepts?

As to the patterns themselves Lakatos is both informative and ingenious. He plays out the history of Euler's theorem in the form of an 
imaginary classroom debate between a teacher and a number of terrifyingly precocious pupils called Alpha, Beta and so on. The pupils adopt different methodological strategies: Alpha throws counterexamples at the theorem and declares it refuted, while Delta defends it by expedient redefinitions and other ploys. The pupils are the spokesmen for the real mathematicians who struggled over the theorem, and the classroom arguments have all been culled from the historical record of this and similar events. Unfortunately this form of presentation has its snags, for again it is abstract. It makes the pattern of debate look as if it depends on nothing more than the personal preferences or the 'intellectual needs' of individuals. ${ }^{18}$ It should in fact be placed in a social framework, and this is where Mary Douglas's theory comes in.

\section{IV}

Anthropologists have given us detailed studies of how different social groups endow their world with intellectual coherence. They have found systematically different conceptions of pollution and dirt, edibility and misdemeanour. The proper ordering of social behaviour and relationships, of household space, the passage of time, and the division of labour are all, in their own way, classifications that must be protected against violation. Since Durkheim, anthropologists have argued that the patterns of domestic and common-place life can often be detected in a group's wider system of classifications: those that range over the animal and plant world, and ultimately over the whole of the natural order. Squabbles over wives and neighbours and illnesses and gifts and contracts find counterparts in beliefs about God and Nature and the great forces that discipline the world. ${ }^{9}$

Why is this? One theory is that men use their ideas about Nature and Divinity to legitimate their institutions. It is put around that deviation is unnatural, displeasing to the gods, unhealthy, expensive, and time consuming. These instinctive ruses map nature onto society. Nature becomes a code for talking about society, a language in which justifications and challenges can be expressed. It is a medium of social inter-action.

Social arrangements can also be used as models with which to grasp the physical or metaphysical order of things. They are a deep well of metaphorical resources, although the conditions which prompt their use in this way are not yet fully understood. But again, the effect is to produce a structural identity between the social and natural orders. ${ }^{20}$ Either way, it is easy to see that classificatory anomalies may take on a moral significance. By these hidden routes they acquire the connotations of irregular social behaviour, which makes a response to them all the more urgent.

One response is to 'taboo' the anomaly which violates the classification, declaring it an abomination and seeing it as a symbol of threat 
and disorder. What were the abominations of Leviticus, asks Mary Douglas, but a list of anomalies to the animal classification so carefully laid down in the Pentateuch. The pig, for example, fails to satisfy all the proper conditions for being a ruminant: it does not both cleave the hoof and chew the cud. This principle also explains why the list includes eels, rock badgers, and others whose status as abominations has always perplexed biblical commentators. Their common characteristic is that they all clumsily straddle the boundary lines of God's demarcations. We shall understand why the Jews did not eat pork when we see the social significance attached to this classificatory scheme.2I

Pollution-conscious societies are usually small, and often rent by competition and conflicting loyalties. They survive by the threat of expulsion, or suffer repeated schism. They are frequently subject to outside threat and consequently their whole system of classification is pervaded by the dichotomy between the good inside and the evil and perverted outside. They need to exercise and symbolize high group control. Strict observance of the group's system of classification distinguishes loyal insiders from traitors and strangers-hence the use of animal taxonomies to impose dietary restrictions. Internal discord is construed in terms of penetration and pollution by outside forces. Among the best examples of such groups are the villages of central Africa which conduct their politics through the idiom of witchcraft accusations. ${ }^{22}$

What an interesting jolt to turn to Lakatos and see that this is exactly how Delta responds to anomalies like the cube with another cube cut out of its middle: 'It is a monster, a pathological case, not a counterexample', he cries. ${ }^{23}$ The same boundary-drawing rhetoric of exclusion is found in Jonquières who says of the picture frame that it is merely a 'polyhedral complex' not a polyhedron 'in the ordinary sense of the word'. ${ }^{24}$ Similarly, Schläfli says of the small stellated dodecahedron that it is not 'a genuine polyhedron'25 and Baltzen goes so far as to say 'It would be more appropriate to find a special name for non-genuine (uneigentliche) polyhedra' (i.e. for those in which $V-E+F$ does not $=2 .{ }^{26}$ )

This whole style of response, which seems to have been very prominent in the history of mathematics, Lakatos dubs 'monster-barring'.27 He could not have hit on a better name. Lakatos further shows his grasp of this consciousness of pollution when he has Delta declare: 'I am gradually losing interest in your monsters. I turn in disgust from your lamentable "polyhedra", for which Euler's beautiful theorem doesn't hold. I look for order and harmony in mathematics, but you only propogate anarchy and chaos. ${ }^{28}$ Again, this rhetoric is not mere fancy on Lakatos's part: he is making Delta paraphrase a letter of Hermite's to Stieltjes, although the topic there is the theory of real functions. 29

It is easy to see how a mathematical counterexample could provoke monster-barring. Imagine a closed group of practitioners with a leadership 
whose authority derives, say, from the discovery of a theorem. A counterexample becomes the basis for a revolution. Rivals can use it as a justification for a take-over. Attitudes towards the counterexample will have to polarize. From one point of view it is indeed the symbol of a monstrous threat. Only the ensuing power struggle will decide whether the anomaly really is, say, a polyhedron or not. Reality has no other basis here. Personal preferences have little role in all this. Suppose a compromiser spoke out. As long as total victory were possible, to adopt the compromise would mean that one side or the other would lose ground; nobody could afford to listen, so polarity and exclusive boundaries would be the form of the knowledge. When the dust settled this is how it would be passed on to others. Explicit propositions about polyhedra will be implicit propositions about society: platonic essences will mirror social power.

Now let us look at a more elaborate response to anomaly. Imagine a large, diverse but stable system of institutions. Many interests have been accommodated in it and complex relations have emerged between the different segments of society. Correspondingly complex conceptual accommodations are needed to justify them and render them intelligible. It is here that elaborate theologies and metaphysics are generated. There will be little anxiety about pollution because there is no simple social dichotomy for it to symbolize. It will be the internal structure of boundaries that will be the focus of concern. The salient feature will be the automatic response to those who disturb the complex equilibrium. The efficacy of received forms and symbols, ritual rather than pollution, will be the theme. Nature will be seen in a way that upholds this pattern; institutional boundaries will be seen as the boundaries between the powers or parts of nature. All this suggests an extensive repertoire of methods for responding to anomaly and for their reclassification. They will be fitted in somewhere, or the classificatory scheme will be expanded. Complicated rites of atonement; promotions and demotions; special exceptions; distinctions, assimilations and legal fictions will abound. And pervading the use of all these expedients there will be a vague sense of overriding unity.

Here again there is the shock of recognition on moving from Natural symbols to Proofs and refutations. These techniques are described in detail in Lakatos's account of what he calls the 'monster-adjustment'30 and the 'exception-barring' ${ }^{\mathrm{I}}$ methods. Monster-adjustment is practised by the casuistical Rho who shows that we can learn to see many of the counterexamples in a way which makes them fit Euler's theorem after all. We have to realize that polyhedra have 'hidden' edges. As Matthiessen put it: 'any polyhedron can be analyzed in such a way that it corroborates Euler's theorem ... In each such case we can show that the polyhedron has hidden faces and edges, which, if counted, leave the theorem $V-E+F$ $=2$ untarnished even for these seemingly recalcitrant cases'. 32 
Exception-barring is equally 'scholastic', accommodating the anomaly by drawing more subdivisions. A boundary can be drawn between the theorem and the acknowledged exceptions to it. All that a counterexample does is to restrict the scope of the theorem: its truth is untouched but the span of its authority, as it were, is narrower than had been thought. It was in this vein that Cauchy, in $182 \mathrm{I}$, said that we were never to 'attribute to formulae an undetermined domain of validity. In reality most of the formulae [in his Cours d'analyse] are true only if certain conditions are fulfilled . . 233 And Bérard in 18 I 8 insisted that 'One should not confuse false theorems with theorems subject to some restriction'.34 (Cf. also Gergonne's description of the way in which Euler's theorem and its exceptions are to be found in separate parts of Lhuilier's memoir, and Zacharias's description of similar widespread compartmentalization.35)

Exception-barring like monster-adjustment also leads to an especially characteristic form of mathematical generality. Here knowledge is additive and segmented-at least in the eyes of its critics. In the case of Euler's theorem the formula $V-E+F=2$ is supplemented by additional terms which accommodate case after case of polyhedra which were exceptions to the original formula. First it becomes $V-E+F=2(n-1)$ for $n$-spheroidal polyhedra, the original formula standing for the special case of monospheroidal polyhedra. Then it becomes:

$$
V-E+F=2-2(n-\mathrm{I})+\sum_{k=1}^{F} e_{k}
$$

for $n$-spheroidal or $n$-tuply-connected polyhedra with $e_{k}$ edges that can be deleted without reduction of the numbers of faces. Then to allow for polyhedra with cavities, the formula blossoms into:

$$
V-E+F=\sum_{j=1}^{K}\left\{2-2\left(n_{j}-\mathrm{I}\right)+\sum_{k=1}^{F} e_{k j}\right\}
$$

To many of the mathematicians who struggled over Euler's theorem this last formula-or variants of it-represented a supreme achievement. It was, they hoped, truly general. $3^{6}$ To these men this sequence of formulae revealed the unfolding of a single principle of order: 'Isn't this a miraculous unfolding of the hidden riches of the trivial starting-point?' asks the later Alpha, marvelling with Plato at the way that 'a single axiom might suffice to generate a whole system'.37

To explain exception-barring and monster-adjustment we need only imagine mathematicians employed in a number of stable but independent institutions. There would be no chance of drumming up support for exclusive boundaries. However loudly the advocates of the counterexample might proclaim that the theorem was refuted, and however vehemently the inventor of the theorem might declare the counterexample to be a monster, their two achievements would live side by side, insulated from one another by an institutional boundary. The public form of the 
knowledge would reflect the relations between their institutions, not their individual states of mind. Gradually others would accept this coexistence as a fact of life. Since neither achievement could be banished, the favoured way of advancing the field would be to invent a device for adding them together. No prizes here for the mathematician who invented an entirely new approach or novel proof procedure. This would not solve the problem of the coexistence of the theorem and counterexample, it would only introduce yet another result to live alongside them. So knowledge will grow in the ad hoc way illustrated above: the diversified pattern of power will leave its mark in formula and method.

Lakatos's own position is that we should reject and improve upon all of the mathematical styles that we have seen so far. Anomalies are to be publicly embraced. Classificatory schemes are expedients which can be discarded, and change opens the way to progress. Of course it may be necessary to take risks like ignoring a few initial refuting instances. Better to set out to prove a conjecture that is already known to be refuted than prematurely abandon it. Only by living on credit for a while can new conceptual resources emerge for future use. $3^{8}$ Now images of social irregularity begin to look attractive:

if you want to learn about anything really deep, we have to study it not in its 'normal', regular, usual form, but in its critical state ... If you want to know functions, study their singularities. If you want to know ordinary polyhedra, study their lunatic fringe ...39

Gone is the old 'horror of counterexamples' with its dogma and conventions and 'monotonous increase in truth'.40

One should always be ready, as Zeta says 'to abandon one's original probiem in the course of solution and replace it by another'.41 After all, who ever said that the term 'Eulerian' occurred in God's blueprint of the universe ? ${ }^{22}$ On the other hand, even if we stay with the same problem, our approach should be to establish 'a unity, a real interaction, between proofs and counterexamples'.43 New forms of classification should put theorem and counterexample in a new light. This method of using counterexamples to deepen a proof Lakatos calls 'the method of proofs and refutations'; it is, he says, a 'dialectical' method.

Is there a social organization which can be seen to generate this style? We must ask what social forms exert a pressure towards innovation and novelty, and encourage transactions across the boundaries of existing classificatory schemes, dissolving them in change? Where is discontinuity more desired than regularity? Where can mistakes be tolerated and risks taken? Where is the tension most acutely felt between the missing of opportunities due to a reluctance to change, and missing them because of lack of sustained application? Which societies embody this contradiction in their very structure? The answer is: individualistic, pluralistic, competitive, and pragmatic social forms. 
Here there can be neither the hope of total and permanent victory nor stable compromise. Now the prizes will indeed go to those who can invent new perspectives rather than preserve the achievements of the past. Knowledge will no longer be fashioned with an eye to the particular and concrete; it will reflect a striving to be universal-or at least as general as the competitive structure that provides its motor. In this competitive environment the question: where is the boundary which separates off 'real' polyhedra? cannot be asked. It has no intellectual meaning because it has no social meaning; there are no stable platonic essences because there are no stable social essences.

\section{V}

Mary Douglas offers a simple way of bringing out the orderly character of the connexions that have just been illustrated. In Natural symbols she shows how these patterns can be expressed in terms of two theoretical dimensions called 'grid' and 'group'.44

The boundary which separates the members of a social group from strangers is called simply the group boundary, and its strength is said to vary from low group to high group. These values are represented by a horizontal line as in Figure I. A very high position on the group axis represents a social group in which the same people work together, take their leisure together, inter-marry, and live in the same neighbourhood. A ghetto is very high group. Where it is possible to evade personal pressures by changing jobs, houses, or friends, the group rating is lower.

The pattern of roles and statuses is thought of as a grid of internal boundaries. Recognizing high grid means looking for extended gradations of rank, of a kind associated with varying rights and duties and expected kinds of behaviour. An army or a bureaucracy is high grid. Open competition, where the only rules are abstract principles of fair comparison, is low grid. High and low grid can be represented by positions along a vertical line. Thus we have:

\begin{tabular}{|c|c|c|}
\hline \multirow[t]{2}{*}{$\begin{array}{l}\text { Grid } \\
\text { axis }\end{array}$} & $\begin{array}{l}\text { High grid } \\
\text { Low group }\end{array}$ & $\begin{array}{l}\text { High grid } \\
\text { High group }\end{array}$ \\
\hline & Low grid & Low grid \\
\hline
\end{tabular}

Figure I. Mary Douglas's Cirid, group diagram showing the four extreme types of social structure 
The grid, group theory applied to Lakatos's data then yields an hypothesis connecting mathematical knowledge, with social structure. The pollution-conscious, monster-barring societies have been described in a way that makes them low on the grid axis but high on the group axis: they are low grid and high group. The more static, complex and diversified societies, preserving continuity by monster-adjustment and exception-barring are high grid and high group. The mere coexistence of theorems and counterexamples, with no effort at all towards synthesis, indicates high insulating boundaries without much group pressure i.e. high grid, low group. Competitive and individualistic societies, where there is always room for innovation and mobility, where the rules of the competitive game are the only accepted social forms, are obviously low grid, low group. The unifying idea of the theory is that the response to anomaly, and hence the drawing of intellectual boundaries, will be negotiated into alignment with the pattern of social boundaries. The full hypothesis is summarized in Figure II :

\begin{tabular}{|c|c|c|}
\hline Grid $\uparrow$ & $\begin{array}{l}\text { Simple coexistence of } \\
\text { theorem and } \\
\text { countercxample } \\
\text { (primitive } \\
\text { exception-barring) }\end{array}$ & $\begin{array}{l}\text { Monster-adjustment and } \\
\text { exception-barring }\end{array}$ \\
\hline & $\begin{array}{l}\text { Dialectical method of } \\
\text { proofs and refutations }\end{array}$ & Monster-barring \\
\hline
\end{tabular}

Figure II. The predicted relation between mathematical knowledge and social structure, derived from Iakatos and Douglas

One observation about this diagram is worth stressing. It should not be supposed that the low grid, low group corner is, in any general sense, an area of low 'social pressure'. It might be tempting to assume that here both knowledge and the individual will be 'free' from society. This is wrong. All that changes is the form of the social pressure, perhaps from personal to impersonal pressure. It would be better to say that the burden of social meaning carried by knowledge is the same everywhere, but even this formulation can be improved upon. Take the pupils in Lakatos's classroom: what they are doing is rehearsing styles of life, and patterns of social interaction, as well as moves in the game of mathematics. But in doing this they are not doing two different things, nor are they doing sometimes the one and sometimes the other; knowledge being what it is, in doing the one they are doing the other. 


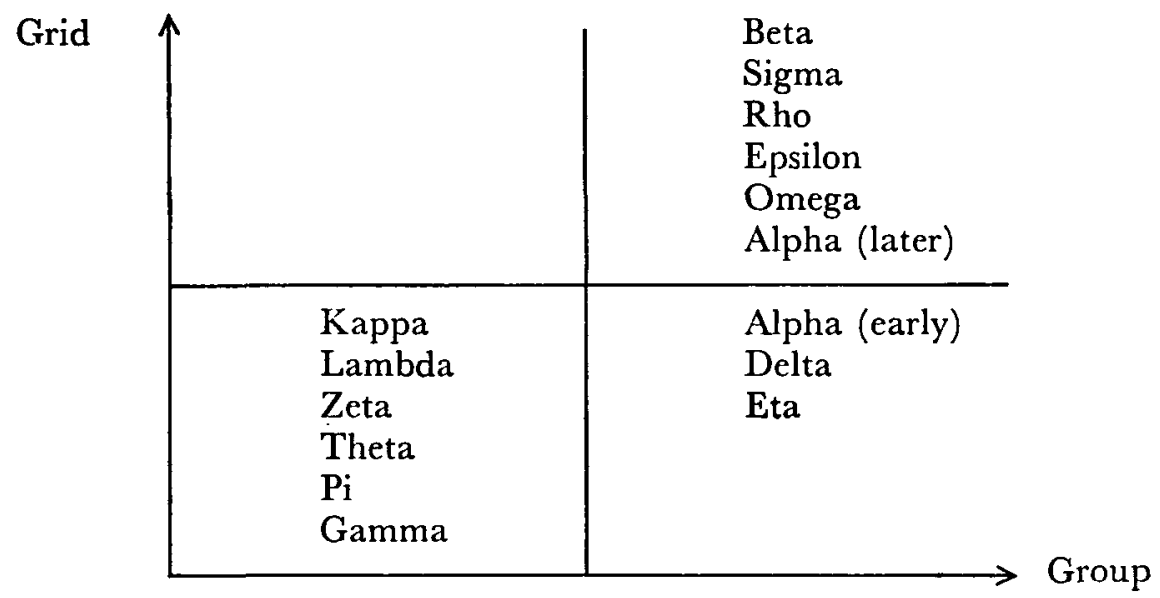

Figure III. The social style implicit in the pupils' response to anomaly

Now for the problem of testing the theory. I shall take it for granted that the problem of assigning a relative grid, group position to an institution, and the problem of recognizing different styles of knowledge can be solved in a rough and ready way. Exhibiting analogies with ideal types or exemplary cases should suffice to test the theory's explanatory power. 45 The issue that I shall discuss is how the theory relates to expressions of individual belief. This will obviously be important because much of the evidence for or against the theory will take this form. For example, if an individual mathematician engages in monster-barring rhetoric and practices, does the theory assert that he must be located in a small, disorganized, or threatened group? Or suppose that we notice something odd about the way that Cauchy responded to star-shaped polyhedra, and we conclude with Lakatos that 'Cauchy knew of them, but his mind was strangely compartmentalized; when he had an interesting idea about star-polyhedra he published it; but he ignored star-polyhedra when presenting counterexamples to his general theorems about polyhedra' ${ }^{6}{ }^{6}$ Does the theory predict that this strange compartmentalization must be a reflection of a compartmentalized high grid, high group environment, and that this is where Cauchy must be socially located?

There is a clear rationale behind individual predictions of this kind. Within a given social setting only certain forms of persuasion and justification will be effective; the rest will fall on deaf ears. It is of no use appealing to group loyalty to put pressure on people if mobility in and out of the group is easy, nor of appealing to what is proper for occupants of a certain role, if everyone else is chopping and changing. Nor, in the case of Cauchy, can one expect more than a collection of disconnected results, if the relevance and meaning of each result is closely tied to one of a number of strongly demarcated roles that he has occupied. By a 
process of selective reinforcement, characteristic forms of argument will emerge in a social setting, standing out by their frequency. This will give each social structure its dominant repertoire of explicit legitimations and its characteristic style of knowledge. The inference to individual behaviour is then justified because of the high probability that individuals will exhibit the characteristic form.

On this basis the following claims about the social location of individual mathematicians would appear to be probable, given the descriptions of their methodological biases in Proofs and refutations:

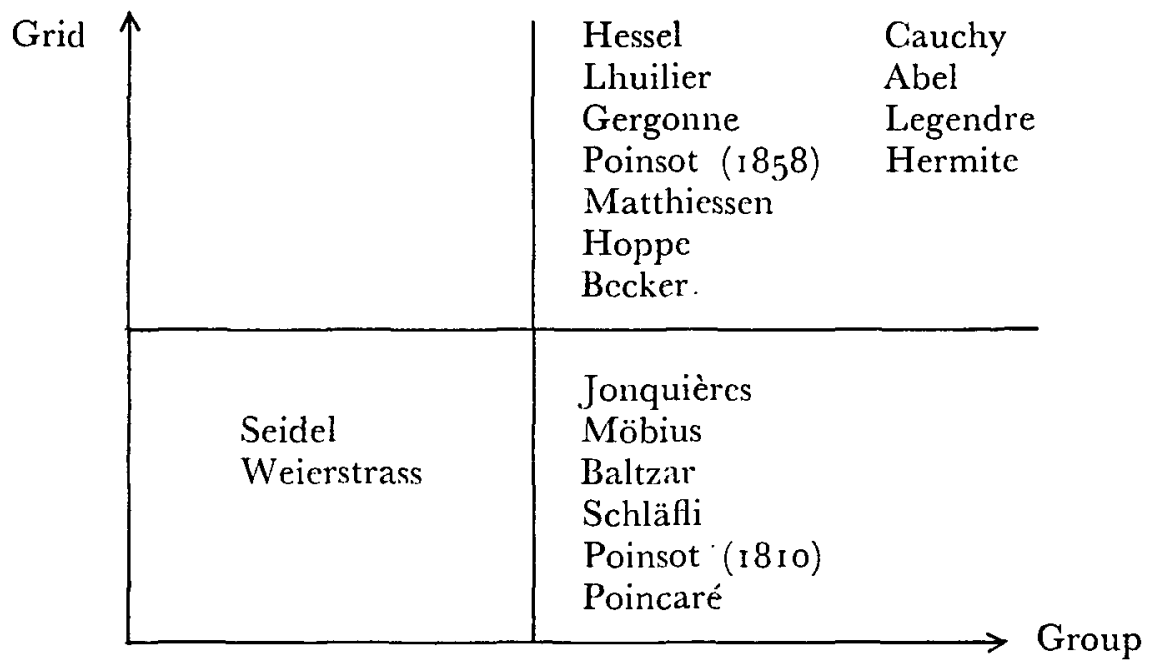

Figure IV. Probable location of individual mathematicians estimated from Lakatos`s text (for cxplanation see below).

Men like Poinsot are interesting here. In 18 ro he was urging counterexamples against the theorem; by 1858 he was engaged in monsteradjustment. The individualistic version of the theory predicts some relevant change in his social milieu to account for this.

Unfortunately, it is easy to see how the basis upon which these predictions are made can be challenged. The problem can be illustrated by appealing once more to Lakatos's pupils in Figure III. On the basis of their professed beliefs I gave the individual pupils widely different positions on the grid, group diagram, assigning them to different social milieus. But is this not wrong, because the pupils were all allegedly intereacting together in a classroom, sharing and creating the same social milieu? Lakatos's own presentation must make the pupils belong together in the low grid, low group, competitive corner of the diagram. Looked at in this way, Proofs and refutations goes against the predicted correlations, and refutes $\mathcal{N}$ atural symbols rather than supports it. 
Of course Lakatos's classroom is a piece of fiction. Perhaps the mathematicians that the pupils represent really were spread out on the diagram in the predicted way. This reply only ducks the issue. The problem is that, in putting pressure on one another, people may try out arguments, use idealized social images, make claims and propose values which taken in isolation 'belong' to other social milieus than the one they occupy. Their utterances may depend more on their goals and aspirations than on their present location.

It is easy to see how this might happen in a low grid, low group environment. There will always be attempts to evade the rigours of competition and secure past achievements, establish monopolies, close group boundaries or reach stable accommodations and understandings. Other positions on the grid, group diagram will, so to speak, all find their advocates. And perhaps this is not peculiar to a competitive social structure. In all social positions men will be trying to push their institutions into other shapes, some wanting to increase mobility and competition, others trying to diminish it. If this is correct, it could destroy any neat correlation between isolated individual utterances and social location.

Obviously this question is an empirical one, but even if the individualistic predictions of the theory turn out to be wrong, the information amassed in refuting them would still be valuable. It would be useful to know if there is any systematic variation in the extent to which individual beliefs cluster around the predicted characteristic style. Does it vary across the grid, group diagram, or change in response to other identifiable circumstances? Perhaps it falls into step with periods of normal or revolutionary science. Or it may be possible to isolate the features of those individuals who do, and those who do not, conform to the predictions of the theory, either socially or psychologically.

There is, however, a less individualistic way of understanding the theory which would survive the failure of predictions of the kind just considered. In this more explicitly sociological version, the theory is to be seen as connecting public, objective forms of knowledge with social structure, and not commenting directly on the beliefs of individuals. After all, society is not a set of individuals, it is a system through which individuals pass, and the theory can be pitched at this structural level. For instance we have seen that if two mathematicians, who are both individually monster-barrers, are forced to coexist the overall style of mathematics is not monster-barring but, say, monster-adjusting. A direct inference to the structure of public knowledge from their isolated individual beliefs would be a mistake, and vice-versa. Individual evidence is always to be treated by putting it in a context where its typicality and its contribution to the overall pattern can be assessed. This overall pattern is precisely the system of boundaries and classifications-it is the style of knowledge-and this is what the theory is about.47 
At first this approach seems to have its dangers. It seems to say that a style of knowledge might be created by a set of individual works, none of which in itself contains or expresses that style through its own make-up. This would mean that the theory would never be informative about individual pieces of work, and could never be invoked to explain them. It would make the style of knowledge merely an aggregative effect that was divorced from the content of knowledge. The example of two monsterbarrers that I have just used shows that this may be true for a while, but only for a while. The overall style, the 'aggregative style' is itself something that can be perceived and known by social actors. It can be taken for granted and accepted as the basis for further work by a third practitioner alongside the two whose works contributed to it. Once this has happened, style in the aggregative sense becomes embodied in individual productions or beliefs. It becomes 'intrinsic style', that is, style which can be detected and exhibitied in individual works, comprising perhaps their unspoken assumptions, or their mode of using established results and resources.

Continuing with the same simplified example we can see that, taken in isolation, the individual works would now amount to two in monsterbarring style, and one in monster-adjusting style; what is more, the latter style may have to be read into the implicit structure of knowledge rather than supported by direct and recorded claims. If this evidence is interpreted individualistically, it would seem but weak support for the grid, group theory: two cases definitely negative, one perhaps positive. Put in context, however, the three cases are mutually supporting and they all contribute to the same picture of a body of knowledge evolving in a way which bears the predicted mark of its social setting. Even in its strictly sociological form, then, there is still an intimate connexion between the theory and individual belief, only now the connexion is more complicated than before, and is itself a matter for detailed enquiry and theoretical interpretation.

\section{VI}

In this section I shall outline and then assess a sociological answer to one of the main historical problems posed by Lakatos's text: why was there a methodological revolution in mathematics in the 1840 ? $\mathrm{He}$ insists that before the I $840 \mathrm{os}$, mathematicians had just not thought of using counterexamples dialectically to squeeze out hidden assumptions and improve their proofs. It 'was virtually unknown in the informal mathematics of the early nineteenth century'. $4^{8}$ 'It never occurred to [Cauchy or Abel] that if they discover an exception, they should have another look at their proof' 49 Well into the nineteenth century,50 monster-barrers, monster-adjusters, and exception-barrers ruled the 
roost. For instance Cauchy thought that he had proved that the limit function of any convergent series of continuous functions was itself continuous; Abel and Fourier knew of exceptions and cited certain series of trigonometric functions. Between I82 I and 1847 , there the matter rested. Not until Seidel invented the concept of uniform convergence was it clear what further restrictions had to be imposed on functions before they obeyed Cauchy's theorem, and what it was about Abel's series that made them exceptions. ${ }^{1}$ Seidel's discovery was, at the same time a quite self-conscious announcement of the new dialectical method of proofs and refutations.

First of all, though, we need to make sure that the question of the mathematical revolution of the 184 os is construed as one about objective knowledge, rather than one of individual thought processes. It is implausible to suggest that a new method of human thought was discovered and exercised by Seidel. What must be at issue is why the natural capability to think dialectically was, allegedly, idosyncratically rather than routinely deployed in mathematics before the 184 os. Lakatos talks of a methodological discovery made by an individual.52 We should talk rather of the inhibiting or the encouraging of public exercises or displays of this methodological style.

Lakatos's own explanation is weak. In effect he says that men failed to make this methodological discovery because they were in the grip of the wrong methodology. 53 To move out of this trivial circle of ideas being used to explain ideas, we need to ask about the dispositions and purposes of those who use them, and these in turn are to be related to the social context. What overriding social preoccupations gripped mathematicians around 1840 ?

Much of the answer to this question is provided by R. S. Turner's fascinating studies of the growth of professorial research in Prussia. $54 \mathrm{He}$ sets out to explain how making discoveries became part of the role of being an academic in Germany. He begins by describing the closed, collegiate character of most eightenth-century German universities: they retained some ancient guild privileges, whilst being constrained by mercantilist limitations on the mobility of students and professors. Above all, they controlled their own appointments, which assured that group loyalties were dominant. As would be expected, these small groups were riven with internal conflict, and charges of corruption and immorality were rife. To this the early years of the nineteenth century added the threat of falling enrolments. The reform ministries which followed the Prussian defeat by Napoleon in 1806 set to work to produce a new school and university system. Spiritually, the universities were to be symbols of regeneration and unity; more practically they were to provide competent schoolteachers and bureaucrats: loyal men of culture and moral probity. This was to be the task of the revived philosophical faculty. Those who 
taught there were to be of the best: intellectuals of wide appeal and renown. To achieve this goal the government bureaucracy took over the control of appointments to university chairs. Ignoring protests, and untouched by the criteria of collegiate acceptability, the bureaucrats used standards that they could understand and manipulate. They read an applicant's publications and they consulted his fellow practitioners throughout Europe. Disciplinary accomplishments were the new criteria, and all the universities had to compete with one another for students, competent professors, and intellectual renown.

The aim was not to produce innnovation but merely to achieve excellence, which could derive either from esoteric scholarship or from grand synthesizing achievements. The growth of detailed learning in particular areas was to be combined with an overriding sense of the organic unity of knowledge. Hence the explicit encouragement given to the specialist seminars in history and philology, as well as the great synthesis of German Idealism.

The result, however, was that competitive specialization prevailed over harmonious accumulation and organic synthesis. The divisive forces of detailed research and the endless pursuit of discovery outweighed the more static group loyalties and the vague philosophical systems which symbolized them. The reason was that making discoveries became a necessity for those who aspired to chairs; the mere compilation, transmission, or refinement of established knowledge in handbooks, translations, and encyclopaedias, was now a thing of the past.

This movement did not come about merely by universities 'reflecting' a general European movement towards competitive individualism, although this was its effect. It was the result of direct administrative intervention, which ironically was largely a reaction against the values of liberalism. Nor, on Turner's account, is the growth of competition in German universities to be explained teleologically by appeal to the institutional requirements of science. Specialization, in fact, occurred in the humanities first, and it was the desire to ape these prestigious and accepted academic forms, and to rid the sciences of the taint of mere utility, that led to their adoption in mathematics and science. The competitive, innovative outcome, which gave Germany her leading role in nineteenth-century science, was the unintended result of the introduction of centalized, bureaucratic appointments criteria.

The connection of Turner's work with Mary Douglas's theory is that he has described the shifting grid and group characteristics of the Prussian universities. It is easy to read his work as a detailed account of small, low grid, high group corporations being reformed with the aim of making them part of a larger high grid, high group system. The consequence, as we have seen, was in fact to create a low grid, low group structure. This sequence is presented in Figure $\mathrm{V}$ below. 


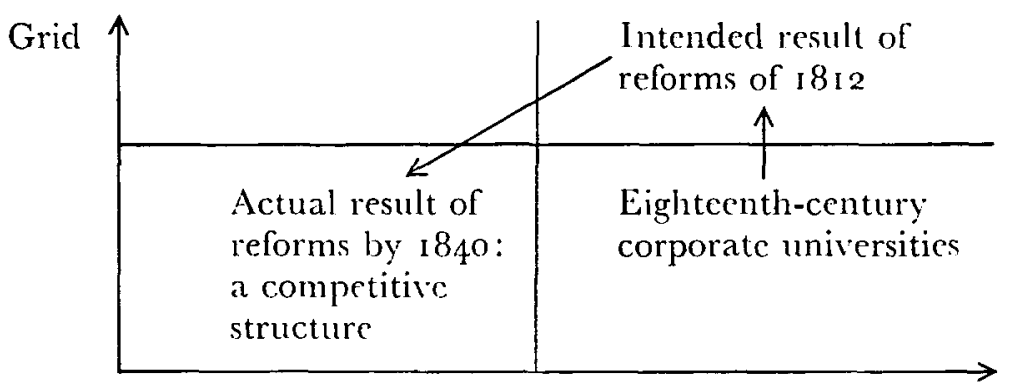

Group

Figure V. Grid, group rendering of Turner's account of Prussian university reform

Turner provides precisely the kind of detailed institutional description which could explain the dating of Lakatos's methodological revolution. Notice that the institutional environment with which he deals is the one that impinges directly on the mathematician qua mathematician. The wider society only has an effect in as far as it impinges on that role. It was precisely by the 184 os that a competitive environment was firmly established in at least one part of the institutional setting of European mathematics. And this environment, of course, is just the one that encourages a dialectical attitude towards proofs and counterexamples. 55

We need to move with caution, however, for Turner's data deals only with Prussia, and Lakatos's hero Seidel, for instance, was based in Munich. $5^{6}$ Turner's findings should be cited in the present context as an example of a type of explanation. Equally detailed accounts of, say, the academic scene in France would perhaps produce a different picture. There would be nothing surprising in finding that certain institutions maintained a closed, elitist, and exclusive structure, successfully swimming against the tide of European social change. What is to be made of this? The most immediate consequence is that we should expect the institutionalized employment of the dialectical method to be patchy. But there is also a more interesting conclusion: that we should resist the temptation to see history as a relentless drift towards low grid, low group, i.e. putting the dialectical method in the vanguard of progress and seeing exceptions as 'cultural lags'.

In the place of this naive progressivist assumption we could put a steady state theory, or some equivalent of geological uniformitarianism. Perhaps we should expect as a general rule that organized groups will circulate round the grid, group diagram: being pushed into competitive relations; hauling themselves back up the group axis; finding themselves hedged in by a grid of bargains and obligations, and so forth. After all, competitive individualism is a very old social form. There are primitive non-technological cultures which are like us in being secular, pragmatic and individualistic. Our world-view is not new; we have been here before. 57 
We should not expect that the emergence of a dialectical method in mathematics is a once-and-for-all phenomenon--a sort of methodological 'big bang'. We may expect it to have faded away in some circumstances after Lakatos's crucial year of I847, and also to have been present well before that date. Earlier cycles through competitive social forms should also reveal mathematicians thinking dialectically.

\section{VII}

I hope that enough has been said to show the utility of taking Mary Douglas's grid, group theory out of its anthropological context and extending it into scientific knowledge. Clearly the approach is not confined to mathematical examples but should illuminate the workings of the natural sciences too. For instance, it should help to show when and why an anomaly is turned into a crisis-provoking anomaly in Kuhn's sense, or why in Lakatos's terms a research programme can be said to be degenerating..$^{8}$ Of course this approach does not deal with all aspects of knowledge. For instance, in the present case it does not illuminate the origin of proof procedures nor the original perception that an object might be deployed as a counterexample.59 But it is hardly a criticism of a theory that it falls short of being a total account of knowledge. In any case, no theory could ever show that knowledge was 'purely social', for our psychological and physical make-up can never be ignored.

One final point is important when assessing the grid, group theory. It is no good having ideas like 'interest' or 'resource' or 'negotiation' or 'image', if they are uncoordinated by a unifying theoretical scheme. At the moment these ideas are typically used in an entirely ad hoc way. ${ }^{60}$ Mary Douglas's theory deserves our attention because it helps to repair this defect. This does not mean that its use will be straightforward or unproblematic; quite the opposite: it will in fact immediately increase the number of problems, for example by throwing into prominence issues that it was previously possible to ignore. But the generation of problems is as much an argument in favour of a theory as an argument against it; it is bound to happen when a diversity of empirical findings and an existing repertoire of concepts are related to a new theoretical idea. Just as Lakatos said that new proof ideas in mathematics actually increase the scope for criticism, so we must expect an explanatory theory to have the same effect in the sociology of knowledge. ${ }^{6 r}$

\section{APPENDIX \\ HOW RADICAL IS LAKATOS?}

There is a striking oddity to be found between the covers of Proofs and refutations, which needs to be made explicit lest it should bias the way the book is understood. I am referring to the content of the editorial 
interventions. Everyone has cause to be grateful to the editors, John Worrall and Elie Zahar, for undertaking the work of publishing Proofs and refutations after Lakatos's death in 1974. But in one way they have discharged their duty oddly: they have inserted a number of editorial footnotes, indicated by an asterisk, in which they hasten to reassure the reader that Lakatos had changed, or would have changed, his mind on certain topics. They stress the achievements of modern logic and emphasize how different it is from the cases which fit Lakatos's approach. It is not difficult to see what prompts these flurries of editorial activity: they happen whenever Lakatos is becoming too radical.

For example, at one point Lakatos makes pupil Kappa say 'conceptstretching will refute any statement' (p. 99). ${ }^{62}$ Any instance of a concept however central or stable it may seem can always be glossed afresh. We have already seen that this is the reason why no theorem ever has a perfectly stable scope or status. Kappa's statement sums up the central thrust of Lakatos's argument. The editors, however, step in to reassure the readers that Kappa 'is wrong to think that . . . one can always produce counterexamples by "concept-stretching", (p. Ioon). Clearly if the editors are right, Lakatos is wrong. Let us examine the matter.

Their argument is that:

By definition, a valid proof is one in which, no matter how one interprets the descriptive terms, one never produces a counter-example-i.e. its validity does not depend on the meaning of the descriptive terms, which can thus be stretched however one likes (p. Ioon).

The nub of their claim can easily be illustrated. The form of the argument 'If all $A$ is $B$, and $C$ is $A$, then $C$ is B', does not depend on the meaning of $\mathrm{A}, \mathrm{B}$, or $\mathrm{C}$. Their meaning can be altered at will without touching the validity of the inference. So the editors are claiming that a proof is really an inferential step, a movement from 'if' to 'then', and it is the validity of the step, not the content of the premise or the content of the conclusion, that matters. This concern with form rather than content is what Russell had in mind in his famous quip that 'mathematics may be defined as the subject in which we never know what we are talking about, nor whether what we are saying is true', ${ }^{3} 3$

The obvious way to reply is to notice that the editors' argument depends on the tacit assumption that only descriptive terms can be stretched and that the logical words in an inference are immune from stretching. A determined Kappa ought to insist that even valid, formal, logical arguments can be made to have counterexamples by stretching the meaning of the terms they contain-why should 'all' and 'some' and 'if' and 'then' be any different from the rest of our language? If Lakatos's position is a really general one, if it is not to be arbitrarily truncated, this is one way that it could go. After all, no one has yet succeeded in separating the 'logical' words in our language from the others and showing that they 
are special in being unstretchable. No principle of an absolute and abstract kind has been found which demarcates them: the existing division is a convention. ${ }^{64}$

There, is, however, a much simpler answer which avoids the need to fight the logician on his own ground. This is that it is false to portray mathematics as if it were essentially a contentless web of inferences. The whole point of Lakatos's material is to remind us of the subtle and substantial character of the concepts A, B, and C that the logician ignores as he slots them into his stereotyped inferential steps. Why does Lakatos's account of mathematics feel more like the mathematics that we have encountered in lecture halls, despite all the shortcomings of pedagogy, than does the work of the logicians? The answer is because he has reversed the order of priority that has dominated the more philosophical accounts. They have let the substance recede into the background and have highlighted the relations between things; Lakatos has reversed the figure and the ground, and highlights the substance of the proofs. He is saying that the important part of mathematics is precisely the content that is left out of account in focusing on the formal, logical relations. How can the relations of conjunction and disjunction, of negation and material implication do justice to processes like imagining that a polyhedron is made of rubber, stretching it flat, constructing the triangulated network, and then removing the triangles one by one? They do not and cannot capture these things, and yet all proofs have some such steps.

There might appear to be a decisive objection to all this. What is it that provides the alleged 'substance' of mathematics? The more we argue that it is not the steps of inference between the premise and conclusion that counts, but the premises and conclusions themselves, the more we need to say what these propositions refer to. If the truths of mathematics are not just true inferences, true 'if thens', they must be true claims about something-but about what? We need to specify an ontology. Are we perhaps forced back into Platonism, into postulating a world of mathematical objects for the theorems to be about? Perhaps Euler's theorem is about a seraphic Ideal Polyhedron after all. It would be sad to have to admit that, because Lakatos rejects 'if thenism', he was after all a tacit Platonist. ${ }^{65}$

Fortunately there is another possibility. We do not have to choose between Platonism and 'if thenism'. The substance of mathematical ideas can be traced back to the material world, to our psychological dispositions, and to a structure of metaphors built upon our experience. We get the idea of what polyhedra are, of what numbers are, of area, distances, rotations, translations, mappings, and of the patterns that can be made with them, all from our experience. Hence the importance of 'quasiexperiments' in Lakatos's account. Of course much more needs to be said, but however unfashionable 'psychologistic' theories of mathematics 
might be, and however odd it may scem to associate then with Lakatos's name, they provide the answer to the objection we are considering. ${ }^{66}$

Another editorial intervention occurs when Lakatos says that we must 'give up the idea that our deductive, inferential intuition is infallible' (p. I $38 \mathrm{n}$ ). The editors announce that this 'passage seems to us mistaken and we have no doubt that Lakatos, who came to have the highest regard for formal deductive logic, would himself have changed it' (p. $138 \mathrm{n}$ ). This exercise in impression-management has some amusing consequences. On p. 52 one of the pupils quotes Poincaré's claim that 'Today absolute rigour is attained'. Lakatos greets this proud boast by 'giggles in the classroom', and in a footnote slyly reminds us that the class is a very advanced one. Directly opposite this (p. 53n) the editors solemnly announce that 'modern logic' has provided us with a precise characterization of validity and that therefore 'logic certainly can make us believe in an argument'. Later they add that once mathematical proofs have been cast into the 'systems' of Russell and Frege, 'There is no serious sense in which such proofs are fallible' (p. $57 \mathrm{n})$. So the editors, at least, did not join in the giggles.

In fact Lakatos provides his own answer to his editors. He has his own reason for rejecting the idea that proofs are to be equated with formal structures of inference from 'if' to 'then'. He says that before the quasi-experiments of informal mathematics can be put into formal logic, they will have to be carefully dismantled and rebuilt in the new, simpler logical material. To change the metaphor: they will have to be re-encoded or translated. All the troubles to which mathematics is heir will not be avoided by casting them into 'infallible' logic, they will only be shifted. Squeezed out of one place they will crop up in another: in arguments about the translation process (p. 123). Worrall and Zahar mention in passing the relevant fact that the translation of mathematics into 'infallible' logic is acknowledged to be fallible, but they make nothing of it. Indeed their position would imply that arguments about this translation process are not arguments about the proof as such, because for them the proof is only the formal structure of the inferences once they have been translated. But this is an evasion; it simply rests on changing the meaning of the word 'proof'. The trend of these editorial interventions is clear. It represents the intrusion of that very philosophy of formalism that Lakatos's book is devoted to outflanking.

How could this strange situation have come about? It surely deserves some explanation. One hypothesis is that the retreat into formalism is the result of anxiety about the uses to which Lakatos's work may be put, for example in sociologically oriented papers such as this. Perhaps it stems from a desire to preserve some small area of unnegotiable objectivity from the relativism which threatens to engulf knowledge. ${ }^{67}$ If this is so, then the historian and the sociologist would do well to ignore the editorial 
blandishments, for they are nought but a strategy for protecting disciplinary boundaries. In terms of the grid, group theory we can suggest that the editors find themselves further up the group axis than did Lakatos, or they are trying to move up that axis by closing ranks. They obviously do not care to take the risks associated with a lower grid, lower group intellectual environment. It would involve them in transactions across established academic demarcations. In short, we can see their retreat into formalism as another case of monster-barring. Perhaps it represents an awareness that Lakatos's work on mathematics is potentially disruptive, at least from the standpoint of the usual philosophical procedures and competences. Such anxiety would be well founded, for Proofs and refutations opens the door to a sociological approach to mathematics. ${ }^{68}$

\section{NOTES}

I Imré Lakatos, Proofs and refutations: the logic of mathematical discovery, Cambridge, 1976.

2 Mary Douglas, Natural symbols: explorations in cosmology, Harmondsworth, 1973.

3 Op. cit. (1), pp. 74-5.

4 Ibid., pp. 139, $144^{-6}$.

5 Ibid., chapter II.

6 Op. cit. (I), p. 34 .

7 Ibid., p. 36.

8 Ibid., p. 13.

9 Ibid., p. 15.

so Ibid., pp. 15-21.

"This technical term is used here in the sense given it by Mary Hesse in her The structure of scientific inference, London, 1974, chapter VIII.

12 Op. cit. (1), p. 87.

13 lbid., p. 151 .

14 Ibid., p. 86.

is Ibid., p. 93 .

${ }_{1}$ Ibid., p. 102.

1 My interpretation of Lakatos's ideas has been influenced by the similarity that they bear to Mary Hesse's general account of scientific concepts given in her op. cit. (11). The negotiability of all predicates or classifications is central to her 'network model'. Lakatos's rejection of a perfectly understood vocabulary of simple terms is essentially the same as Hesse's rejection of the pure 'observation language' of empiricism. The general structural features of our network of knowledge, Hesse's 'coherence conditions', are at least in part provided by Lakatos's strategies for responding to counter examples.

To see Lakatos as arguing that all classifications and hence all theorems and proofs are negotiable is a reading of Lakatos that has been challenged by, of all people, his own editors. This important matter is discussed in the appendix at the end of this paper.

is Op. cit. (1), p. 29.

19 The classic statement is E. Durkheim and M. Mauss, Primitive classification, London, 1963 (first published $\mathrm{r}$ g०3). For two detailed studies in this tradition see R. Bulmer "Why is the cassowary not a bird? A problem of zoological taxonomy among the Karam of the New Guinea highlands', Man, 1967, 2, 5-25, and S. J. Tambiah, 'Animals are good to think and good to prohibit', Ethnology, 1969, 8, 424-59.

20 $\mathrm{R}$. Horton argues that in primitive societies social structures provide models for nature because social knowledge is the most stable intellectual resource available. See his 'African traditional thought and western science', Africa, 1967,37, 50-71, 155-87. For a mathematical example in which the social is appealed to as a metaphor, see Paul Forman, 'Weimar culture, causality, and quantum theory, 1918-1927: adaptation by German physicists and mathematicians to a hostile intellectual environment', Historical studies in the physical sciences, $1971,3,1-1$ I 5 . Section II.4 on intuitionism vividly illustrates the way images of a cultural crisis were used to characterize and create a sense of mathematical crisis. This episode can also be read as an example of concept-stretching, where a deliberate restriction in the scope of accepted mathematical procedures is advocated in order to produce counter-examples and anomalies where previously none had existed. 
1" The original theory, that the abominations were category-violators was proposed by Mary Douglas in Purity and danger: an analysis of concepts of pollution and taboo, London, 1966 . A developed version of the theory which describes the historical circumstances which gave special significance to eating pork is to be found in her Implicit meanings: essays in anthropology, London, 1975, chapter XVII.

22 See Douglas, op. cit. (2), p. 87.

${ }_{23}$ Op. cit. (1), p. 14.

24 Ibid., p. 21 .

25 Ibid., p. 17 .

26 Ibid., p. 16.

27 Ibid., p. 14.

38 Ibid., p. 19.

9 Ibid.

30 Ibid., p. 30.

3* Ibid., p. 24.

32 Ibid., p. 39 .

33 Ibid., p. 26.

34 Ibid., p. 24.

35 Ibid., p. 36 .

${ }^{6}$ Ibid., pp. 79, 97.

37 Ibid., p. 81 .

38 Ibid., p. 75 .

39 Ibid., p. 23.

40 Ibid, pp. 4, 5, 37.

11 Ibid., p. 68.

42 Ibid.

43 Ibid., pp. 30, 37.

44 These dimensions were first introduced in Douglas, op. cit. (2), chapters IV and VI. The form of the diagram used on p. 129 will be followed here rather than the earlier, somewhat more complicated, figures.

45 This theory has been applied to interview data from contemporary scientists by C. Bloor and D. Bloor 'Does grid and group apply to industrial scientists? An empirical test of Mary Douglas's theory' (forthcoming, 1978. Paper read at Professor Douglas's seminar, University College, London, 23 November 1976 ). Here empirically-based grid, group ratings are constructed for individual scientists, and checked against their attitudes to science. This provides a detailed illustration of the concepts of the grid, group theory in action. The most detailed statement of the various 'cosmologies' generated by different grid, group positions is to be found in Mary Douglas, Cultural bias (Occasional papers of the. Royal Anthropological Institute of Great Britain and Ireland, No. 34), London, 1978.

46 Op. cit. (1), p. 84 .

47 The biologist Bateson used to say that plants were not matter, but systems through which matter passed; cf. W. Coleman 'Bateson and chromosomes: conservative thought in science', Centaurus, 1970, 15, 228-314. I have used this striking idea in the above paragraph. For a valuable discussion of 'structural' explanations in sociology, and a comparison with such explanations in other branches of science, sec S. B. Barnes Interests and the growth of knowledge, London, 1977, chapter III.

$4^{8}$ Op. cit. (1), p. $4^{8}$.

49 Ibid., P. 55.

50 Ibid., p. 81 .

51 Ibid., p. 131.

32 Ibid., p. 136 .

53 I bid.

$54 \mathrm{R}$. Steven Turner, 'The growth of professorial research in Prussia, 1818-1848-causes and context', Historical studies in the physical sciences, 1971, 3, 137-82; 'University reformers and professorial scholarship in Germany, 1760-1806', in L. Stone (ed.), The university in society, Oxford, 1975, ii, 495-531.

5s Turner's account may be compared with $\mathrm{J}$. Ben-David's earlier treatments of the same episode, summarized in The scientist's role in society: a comparitive study, Englewood Cliffs, 1971, chapter VII. The two accounts agree on the main point that a competitive system was established around the middle of the nineteenth century.

${ }^{6} \mathrm{~J}$. C. Poggendorff (ed.), Biographisch-literarisches Handworterbuch zur Geschichte der exakten Wissenschaften, Leipzig, 1863 , ii. 896-7.

57 See for example the description of the 'Big-men' societies of New Guinea in Mary Douglas, op. cit. (2).

$5^{8}$ For example Eugene Frankel in 'Corpuscular optics and the wave theory of light: the science and politics of a revolution in physics', Social studies of science, 1976, $6,141-84$, describes 
how a power struggle between supporters and opponents of Laplace in the Paris Académie des Sciences precipitated a crisis in the corpuscular theory of optics. His account would appear to fit well with the description of monster-barring versus theorem-barring in high group, low grid communities. Another example is provided by the same institution a little later, only this time the monster-barrers won. This was when Pasteur disposed of the 'incompetent' experiments of Pouchet who believed in spontaneous generation. See J. Farley and G. Geison, 'Science, politics and spontaneous generation in nineteenth-century France: the Pasteur-Pouchet debate', Bulletin of the history of medicine, $1974,48,161-98$.

59 This does not mean that the theory can never contribute towards such an understanding, or that such subjects fall outside the scope of sociology; far from it. Proof procedures may often arise by an extension of existing ones that have become customary, or they may be explained by social interests highlighting empirical processes which may be made the basis of new procedures. For example see the accounts of how eugenic concerns influenced the growth of Galton's and Pearson's statistical ideas in Ruth S. Cowan, 'Francis Galton's statistical ideas: the influence of eugenics', Isis, $1972,63,509-28$, and D. MacKenzie, "The development of statistical theory in Britain, 1865-1925: a historical and sociological perspective', University of Edinburgh PhD thesis, 1978 .

60 Notice for instance the lack of unifying theory in S. B. Barnes, Scientific knowledge and sociological theory, London, 1974, and D. Bloor, Knowledge and social imagery, London, 1976.

6x The problems I have in mind are, for example: how do the concepts of grid and group relate to the idea of role? Can there really be a unique grid, group rating for an individual as he moves from role to role? Or take the case of the followers of Weierstrass represented as low grid, low group. They were put here because of their dialectical methodology and their initial rejection of monster-barring, etc. But their attitude to counterexamples produced later by Cantor's work was precisely to resort to monster-barring (Lakatos, op. cit. (1), p. 50). This subtle pattern of different methodologies being adopted in different circumstances, governed by the varying demands of expediency, is a problem which awaits the theory. Cf. also the way Jonquieres used 'monster-barring against cavities and tunnels but monster-adjustment against crested cubes and star-polyhedra', (Ibid., p. 38). But only those who want to see the theory fail will assume at this stage that these problems are refuting instances.

62 All page references in the appendix are to Lakatos, op. cit. (1).

${ }_{63}$ Bertrand Russell, Mysticism and logic, London, 1963 (first published 19 10), p. 59 .

64 In 1935 Tarski posed the problem of how to demarcate logical words from others. Popper thought that he had solved the problem in 1947 , but is now of the opinion that he failed, and is sceptical about future success. C. Karl Popper, 'Logic without assumptions', Proceedings of the Aristotelian Society, 1947, 47, 251-92, and 'Replies to my critics' in P. A. Schilpp (ed.), The philosophy of Karl Popper, La Salle, 1974, p. I og6. The fact is that logical words are stretchable. For example they had to be stretched to cope with the introduction of the truth table method.

65 For a clear description of 'if-thenism' see Alan Musgrave, 'Logicism revisited', British journal for the philosophy of science, 1977, 28, 99-127. On p. i23 Musgrave suggests that Lakatos's account of mathematics rests on a naive Platonism.

${ }^{66} \mathrm{~J}$. S. Mill's despised 'psychologistic' theory of mathematics has recently been defended and developed in D. Bloor, op. cit. (6o), chapter V.

67 For Popperian rhetoric against the threatening 'tide of subjectivist relativism' see Alan Musgrave, 'The objectivism of Popper's epistemology', in P. A. Schilpp (ed.) op. cit. (64), p. 588 .

${ }_{68}$ Instead of retreating back into formalism the editors might have helped rather than hindered the development of Lakatos's research programme by drawing attention to other work in logic and mathematics of a similar tendency. For instance, those impressed by Lakatos's achievement would have much to learn from Alfred Sidgwick's direct and forceful attack on formal logic in his The use of words in reasoning, London, 1901 . He too had reached the conclusion that 'To offer proof is to offer definite points of attack' (p. 82). Sidgwick shares Lakatos's attitude to counterexamples: 'The difference of method proposed is not that between attending only to rules and attending only to exceptions, but between avoiding and welcoming the discovery of exceptions to rules' ( $p$. 1 3o). But if there is any book that deserves detailed comparison with Proofs and refutations it is Wittengstein's Remarks on the foundations of mathematics, Oxford, 1964. Both writers reject the usual view of mathematics having its 'foundations' in a trivial logical starting point; both are aware of the contrived and distorted effect of translating living and growing concepts into the impoverished apparatus of formal logic; both are masters of the art of spotting alternatives to steps in reasoning which look 'compelling', or conclusions which look 'inevitable'; both have, in one sense of the word, a 'finitist' picture of mathematical proof; both are profound critics of the glib 'Platonism' or 'Realism' so prevalent in logic and mathematics. Indeed, what gives their work its force is the fact that both men are deeply responsive to the social dimension of knowledge. 